Original Research Article

\title{
Simultaneous enrichment/determination of six sulfonamides in animal husbandry products and environmental waters by pressure-assisted electrokinetic injection coupled with capillary zone electrophoresis
}

\author{
Shixuan Yang ${ }^{\mathrm{a}, \mathrm{b}}$, Suya Ma ${ }^{\mathrm{b}}$, Kongli Zhu ${ }^{\mathrm{c}}$, Minglin Wang ${ }^{\mathrm{a}, *}$, Jinhua $\mathrm{Li}^{\mathrm{b}, *}$, Maryam Arabi ${ }^{\mathrm{b}}$, \\ Huitao Liu ${ }^{\mathrm{d}}$, Yin $\mathrm{Li}^{\mathrm{e}}$, Lingxin Chen ${ }^{\mathrm{b}, *}$ \\ ${ }^{a}$ College of Food Science and Engineering, Shandong Agricultural University, Tai'an, 271018, China \\ ${ }^{\mathrm{b}}$ CAS Key Laboratory of Coastal Environmental Processes and Ecological Remediation, Research Center for Coastal Environmental Engineering and Technology, Yantai \\ Institute of Coastal Zone Research, Chinese Academy of Sciences, Yantai 264003, China \\ 'Inspection and Testing Center of Yinan County, Shandong, Yi'nan 276300, China \\ ${ }^{\mathrm{d}}$ College of Chemistry and Chemical Engineering, Yantai University, Yantai 264005, China \\ ${ }^{\mathrm{e}}$ Naval Aviation University, Yantai 264001, China
}

\section{A R T I C L E I N F O}

\section{Keywords:}

Online enrichment

Antibiotics

Capillary zone electrophoresis (CZE)

Food analysis

Food composition

Seawater

\begin{abstract}
A B S T R A C T
Pressure-assisted electrokinetic injection (PAEKI) as the online method was developed for the simultaneous enrichment of six sulfonamides (SAs), including sulfamethazine (SMZ), sulfamerazine (SMR), sulfamonomethoxine (SMM), sulfadizine (SDZ), sulfamethoxazole (SMX) and sulfacetamide (SFA) in different animal husbandry products and environmental waters samples, followed by capillary zone electrophoresis (CZE) determination. Various parameters affecting the separation performance of CZE and the enrichment efficiency of PAEKI were optimized in detail. Under optimal conditions, the six SAs were completely separated within 8.5 min, and the enrichment factors for SMZ, SMR, SMM, SDZ, SMX and SFA were 39, 47, 53, 50, 54 and 62 folds, respectively, compared with the direct CZE. The limits of detection (LOD) ranged from $0.0018-0.0163 \mu \mathrm{g} / \mathrm{mL}$, $0.0083-0.0638 \mu \mathrm{g} / \mathrm{mL}$ and $0.0052-0.0478 \mu \mathrm{g} / \mathrm{mL}$ in milk, pork and egg samples, respectively, as well as limits of quantification (LOQ) within $0.0061-0.0503 \mu \mathrm{g} / \mathrm{mL}, 0.0253-0.1826 \mu \mathrm{g} / \mathrm{mL}$ and $0.0164-0.1475 \mu \mathrm{g} / \mathrm{mL}$, respectively. Tap water, lake water and seawater were also examined for investigation of applicability of the proposed method. Satisfactory recoveries in the range of $89-113 \%$ were obtained with the three spiked food samples, and the relative standard deviations were from 1.6 to $7.3 \%$. Simple and effective online enrichment method provides a promising perspective for CZE measurements of SAs in complex matrices with high accuracy, sensitivity and rapidity.
\end{abstract}

\section{Introduction}

Sulfonamides (SAs), the earliest synthetic antimicrobial agents, are widely used in animal husbandry and veterinary clinic to prevent and treat food-borne animal diseases due to their broad antibacterial spectrum, convenient use, low cost and good curative effect (Pérez et al., 2016; Xia et al., 2017; Santos et al., 2004). The six kinds of SAs (Fig. 1) of sulfamethazine (SMZ), sulfamerazine (SMR), sulfamonomethoxine (SMM), sulfamethoxazole (SMX), sulfadizine (SDZ) and sulfacetamide (SFA) are commonly used (Chen et al., 2019; Lahcen et al., 2019; Lara et al., 2009). However, improper use or abuse of such antibiotics in veterinary medicine poses a significant potential risk of residues in edible tissues. The main risk to human health in using antibiotics on animals is the fact that animal bacteria can produce resistance to drugs, mainly by using sub-therapeutic doses. This resistance can be produced through several pathways such as mutation, acquisition of resistant genes or a combination of both (Hoff and Kist, 2009). Another major issue with the extensive use of SAs and other drugs in intensive animal production is the transfer to the environment through residues in animal feces (Wang et al., 2020). Although the residual concentration of SAs in food and environmental water sample is mostly in trace level, they may cause potential adverse side effects to human beings, such as allergic, other long-term health effects, or even cancer (Dasenaki and Thomaidis, 2010). To safeguard human health, the European Union (EU) has established a maximum residue limit (MRL) of $100 \mu \mathrm{g} / \mathrm{kg}$ (or $100 \mathrm{ppb}$ ) for the total amount of SAs in food samples of animal-origin

\footnotetext{
* Corresponding authors.

E-mail addresses: mlwang1963@163.com (M. Wang), jhli@yic.ac.cn (J. Li), 1xchen@yic.ac.cn (L. Chen).
} 
<smiles>Cc1cc(C)nc(NS(=O)(=O)c2ccc(N)cc2)n1</smiles>

Sulfamethazine(SMZ) $\mathrm{pKa}=7.4$<smiles>COc1cc(NS(=O)(=O)c2ccc(N)cc2)ncn1</smiles>

Sulfamonomethoxine (SMM) $\mathrm{pKa}=6.5$<smiles>Cc1cc(NS(=O)(=O)c2ccc(N)cc2)no1</smiles>

Sulfamethoxazole (SMX)<smiles>Cc1ccnc(NS(=O)(=O)c2ccc(N)cc2)n1</smiles>

Sulfamerazine (SMR) $\mathrm{pKa}=6.8$<smiles>Nc1ccc(S(=O)(=O)Nc2ncccn2)cc1</smiles>

Sulfadizine (SDZ) $\mathrm{pKa}=6.4$<smiles>CC(=O)NS(=O)(=O)c1ccc(N)cc1</smiles>

\section{Sulfacetamide(SFA)} $\mathrm{pKa}=\mathbf{5 . 3}$

Fig. 1. Chemical structures and $\mathrm{pKa}$ values of the six SAs analyzed in this work.

such as animal husbandry products (Pérez et al., 2016; Premarathne et al., 2017; Xia et al., 2017). Therefore, it is necessary to develop simple, convenient, efficient and sensitive methods for monitoring and quantifying SAs residues.

So far, the most common analytical approaches for SAs determination mainly include immune analysis (Shelver et al., 2008), gas chromatography-mass spectrometry (GC-MS) (Sacher et al., 2001), high performance liquid chromatography (HPLC) (Qi et al., 2018), capillary electrophoresis (CE) (Sun et al., 2013), liquid chromatography-tandem mass spectrometry (LC-MS/MS) (Martins et al., 2016) and biosensing analysis (Mohammad-Razdari et al., 2019). Among them, CE is more preferable compared with others for SAs residue analysis as a liquid phase separation technique due to the following reasons. Firstly, CE is efficient and fast in separating target analytes in a relatively short period of time (Brugnerotto et al., 2019). Secondly, the consumption of sample and solvent as well as waste generated is minimum (Fuh and Chu, 2003). The experiment consumes only a few milliliters of electrolyte solution and nanoscale sample volume (Lu et al., 2017). Thirdly, CE has several separation modes such as capillary zone electrophoresis (CZE) (Lechtenberg and Hensel, 2019) and micellar electrokinetic chromatography (MEKC) (Ma et al., 2013), which have high degree of automation and can be utilized in the wide range of applications. However, the sensitivity of CE-UV detection is always limited due to the small injection volume and narrow optical path (Li et al., 2011), while the online (on-column) enrichment can effectively improve this defect. As the unique enrichment technique of $\mathrm{CE}$, the online enrichment can be carried out facilely, in an easy and convenient way, adjusting the electrolyte solution composition, the sample matrix composition, and the sample injection procedure (Gao et al., 2019).

The CE online enrichment modes generally include large-volume sample stacking (LVSS) (Memon et al., 2019), electrokinitic supercharging (EKS) (Chui et al., 2017), sweeping (Zhang et al., 2019), isotachophoresis (ITP) (Jastrzebska et al., 2015) and pressure-assisted electrokinetic injection (PAEKI) (Zhang et al., 2011a, 2011b). Amongst them, PAEKI is the combination of electrophoresis and electroosmotic flow (EOF) that allows ions to enter the capillary under the action of an electric field to achieve stacking, and can provide powerful enrichment function without affecting the separation efficiency (Zhang et al., 2011a, 2011b). Specifically, as schematically shown in Fig. 2, when the sample solution containing analytes with low conductivity enters a filled capillary containing high conductive background electrolyte (BGE) solution, the mobility of analytes would change from high-speed to low-speed, because the conductivity is inversely proportional to the field strength (Yi et al., 2018). Moving from the sample zone to the BGE zone, the analytes slow down suddenly due to a decrease in the field strength, leading to "stacking" of analytes at the sample-BGE boundary (He et al., 2019). The existence of water plug can inhibit EOF, change the migration rate (Chen et al., 2015a, 2015b) and improve the reproducibility of experimental results (Chen et al., 2015a, 2015b). The water plug provides an enhanced electric field at the injection end of the capillary than the BGE solution (Wang et al., 2019), and carries charged analytes in the capillary like a highway. After the analytes have accumulated at the sample-BGE boundary, under electric field, an opposite pressure to the direction of EOF is provided at the injection port to balance EOF (Xu et al., 2014), thereby increasing the injection volume of analytes and achieving the effect of online enrichment. Since the PAEKI method can readily realize the enrichment of analytes just by simply modulating the parameters of CE apparatus, it is a good choice for separation and determination of various compounds (D'Ulivo and Feng, 2015; Li et al., 2016; Ma et al., 2019).

Herein, an online PAEKI for the simultaneous enrichment of six SAs was proposed followed by CZE determination. The main parameters affecting the PAEKI-CZE process were optimized, including electrolyte solution, organic additive, injection and separation voltage, assisted pressure, injection time and water plug. Under the optimal conditions, PAEKI-CZE was well validated and successfully applied to the 


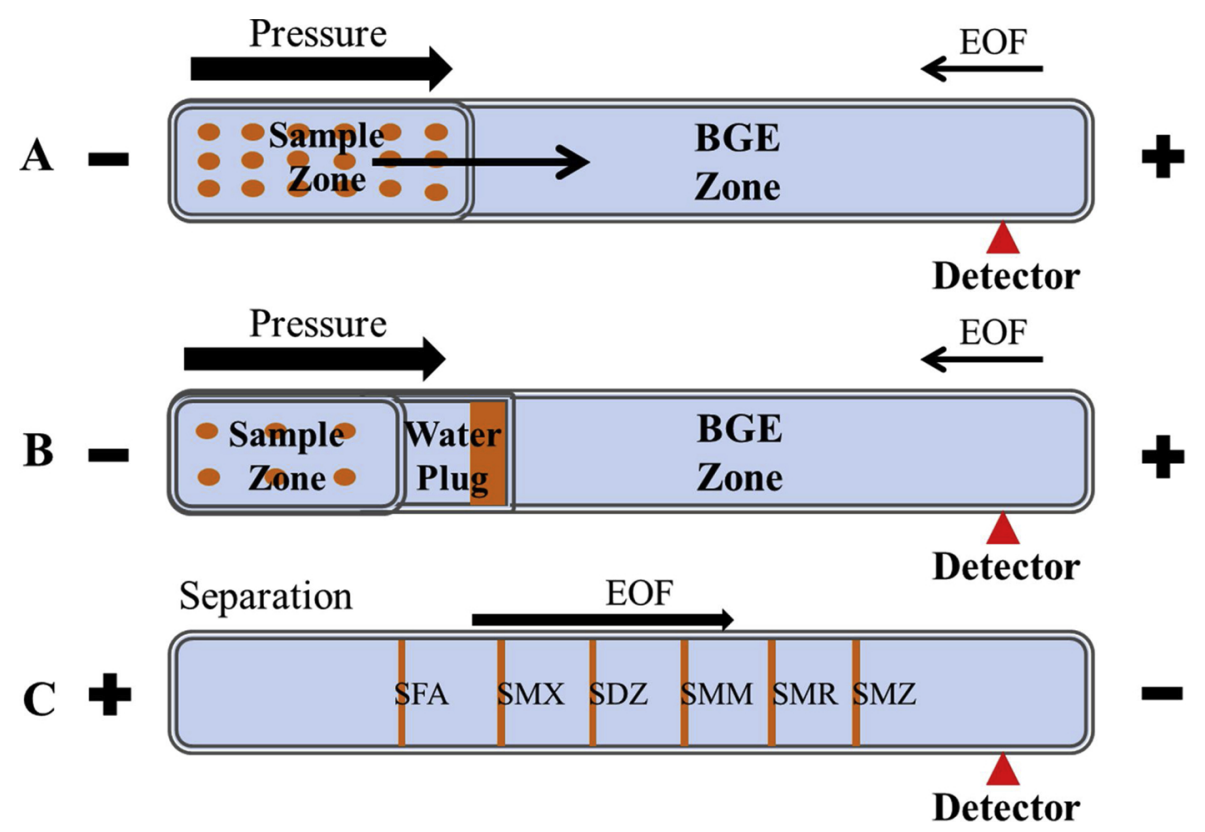

Fig. 2. Schematic illustration of the PAEKI-CZE procedure.

determination of SAs in three animal husbandry products (milk, pork, egg) and three water samples (tap water, lake water and seawater).

\section{Experimental}

\subsection{Reagents and samples}

HPLC grade SAs standards, including sulfamethazine (SMZ), sulfamerazine (SMR), sulfamonomethoxine (SMM), sulfadizine (SDZ), sulfamethoxazole (SMX) and sulfacetamide (SFA) were provided from Sigma-Aldrich (Steinheim, Germany); their chemical structures and $\mathrm{p} K_{\mathrm{a}}$ values were shown in Fig. 1. Standard stock solutions containing 1000 $\mathrm{mg} / \mathrm{L}$ of each SA were prepared by dissolving the required amounts of the standards in methanol $(\mathrm{MeOH})$, owing to their quite low aqueous solubility (Li et al., 2009; Cysewski and Jeliński, 2019), and standard working solutions were obtained by diluting the standard stock solutions with ultrapure water, in favor of $\mathrm{CE}$ analysis; the stock and working solutions were all stored in a refrigerator at $4{ }^{\circ} \mathrm{C}$ until use. Relevant descriptions about the solubility of e.g., SMX in ultrapure water were given in the ESI. Chromatographic pure $\mathrm{MeOH}$, ethanol (EtOH), acetone and acetonitrile (ACN) were all purchased from J\&K Chemical (Beijing, China). Analytical pure acetone, ethyl acetate and nhexane were applied from $\mathrm{Fu} \mathrm{Yu}$ Fine Chemical (Tianjin, China). Anhydrous sodium sulfate $\left(\mathrm{Na}_{2} \mathrm{SO}_{4}\right)$, sodium hydroxide $(\mathrm{NaOH})$, sodium tetraborate decahydrate $\left(\mathrm{Na}_{2} \mathrm{~B}_{4} \mathrm{O}_{7} \cdot 10 \mathrm{H}_{2} \mathrm{O}\right)$, disodium hydrogen phosphate $\left(\mathrm{Na}_{2} \mathrm{HPO}_{4}\right)$ and sodium dihydrogen phosphate $\left(\mathrm{NaH}_{2} \mathrm{PO}_{4}\right)$ were obtained from Sinopharm Chemical Reagent (Shanghai, China). Ultrapure water with the specific resistance of $18.2 \mathrm{M} \Omega \mathrm{cm}$ produced by Pall Cascada $^{\mathrm{TM}}$ lab water purification system (Pall Corp., Massachusetts, USA) was used for aqueous solution preparation throughout the study, except specified.

Milk, pork and eggs samples were purchased at the local supermarket (Yantai, China). The pre-treatment procedure of milk sample was based on the previous literature (Parab and Amritkar, 2012) with slight modification by adding the use of n-hexane. After fully mixing, the components of milk will be evenly distributed and the randomness of sampling will be increased. $1 \mathrm{~mL}$ of milk was taken into a $10 \mathrm{~mL}$ centrifuge tube and vortexed for $30 \mathrm{~s}$. Then, $3 \mathrm{~mL}$ of ACN was added and vortexed for $3 \mathrm{~min}$ to precipitate protein (preventing the protein from clogging the capillary column) and extract the analytes from the milk. After centrifuging at $3800 \mathrm{rpm} / \mathrm{min}$ for $10 \mathrm{~min}$, the supernatant was taken out, $2 \mathrm{~mL}$ of $\mathrm{n}$-hexane was added and sonicated for $10 \mathrm{~min}$ to effectively remove lipids from the milk extract, then centrifuging again to remove the supernatant, and blowing with nitrogen to dryness to obtain yellow residue. The main difference from the literature (Parab and Amritkar, 2012 is that we added n-hexane to remove the lipids from the milk, because we had shown experimentally that there is no way to completely prevent the oil layer from being mixed into the extract, which would cause errors in the experimental results, and would get into and contaminate the capillaries. In addition, the residue was dissolved with $800 \mu \mathrm{L}$ of ACN-water v:v, 5:95 solution to reduce experimental errors since the main components of electrolyte solution used in the CZE were ACN and water, followed by vortexing for $3 \mathrm{~min}$. All of them were taken out into a $1.5 \mathrm{~mL}$ centrifuge tube, centrifuged at $4{ }^{\circ} \mathrm{C}$ for $5 \mathrm{~min}$ with $13,000 \mathrm{rpm} / \mathrm{min}$, and then the supernatant was filtered with $0.22 \mu \mathrm{m}$ water phase filter membrane for injection analysis.

As for the pork sample, it was smashed into meat paste by a cooking machine. Then add appropriate amount of anhydrous sodium sulfate, ACN and ethyl acetate to remove water, precipitate protein and extract fat, respectively (Wang and Luo, 2018). After vortexing and shaking, the mixer was centrifuged and the supernatant was placed in a round bottom flask. Then repeat the above steps, and so the supernatants of the two times were combined. After extracting the fat with n-hexane, the liquid in the lower layer was dryed. Before analysis, $2 \mathrm{~mL} \mathrm{ACN/}$ water $(5: 95, v / v)$ solution was used to dissolve and then filtering with filter membrane. As for the egg sample, it was placed in a beaker and stirred until evenly mixed. Then add appropriate amount of anhydrous sodium sulfate, ACN and ethyl acetate to remove water, precipitate protein and extract fat, respectively (Pan et al., 2016). After vortexing and centrifuging, the supernatant was transferred to a round bottom flask, then do it again. In this process, attention should be paid to the use of glass rods to stir up agglomerated residue and wash the glass rods. Similarly, the extract is blow-dried, redissolved and filtered. More details of the pork and egg pretreatment processes were given in the ESI.

All water samples were collected by using the clean and dry $500 \mathrm{~mL}$ glass beakers produced by Shuniu Glass Instrument Co., ltd., (Sichuan, China), and $200 \mathrm{~mL}$ were sampled. The tap water sample was taken from the laboratory as needed and was collected after flowing for $5 \mathrm{~min}$ to ensure a free flow. The lake water sample was collected from an artificial lake located in the schoolyard of Yantai University. When 
taking a sample of lake water, the beaker was held by hands and rinse the beaker with water sample before sampling, as well as taking the sample of seawater. The seawater sample was collected near freshwater fisheries in the Huanghai Sea. The beaker was flushed with tap water, lake water and seawater three times respectively before taking samples. All samples were stored in the dark at $4{ }^{\circ} \mathrm{C}$ until use. Before use, all the water samples were passed through microporous nylon filters with pore sizes of $0.45 \mu \mathrm{m}$ in diameter.

\subsection{Instrumentation}

All electrophoresis experiments were performed on a SCIEX P/ ACETM MDQ plus CE system (Fullerton, CA, USA) equipped with a DAD. Bare fused-silica capillary (inner diameter $75 \mu \mathrm{m}$, outer diameter $375 \mu \mathrm{m}$, total length $50.2 \mathrm{~cm}$, effective separation length $40 \mathrm{~cm}$ ) was brought in Yongnian Optical Fiber Factory (Hebei, China). Data were collected using a Beckman P/ACE workstation version 32 Karat software. The $\mathrm{pH}$ was regulated by PHS-3C digital $\mathrm{pH}$ meter (Hangzhou Dongxing Instrument Factory, Hangzhou, China). During the pretreatment of pork samples, the pork was crushed with a MX-GS1 multifunctional hand-held electric cooking machine (Panasonic co., ltd., Japan). The extracted liquid was dried by ST-A12 nitrogen blower (Guangzhou Shitai Environmental Protection Technology Co., Ltd., Guangdong, China).

\subsection{CZE conditions}

The new capillary should be initialized by rinsing with water for 10 $\min , 1.0 \mathrm{M} \mathrm{NaOH}$ for $40 \mathrm{~min}$, water for $10 \mathrm{~min}$ and electrolyte solution (BGE) for $30 \mathrm{~min}$ before use. The capillary was flushed water (2 min), 1 $\mathrm{M} \mathrm{NaOH}$ (10 min), water and buffer solution (5 min) respectively before the experiments every day. The BGE solution was made of $20 \mathrm{mM}$ $\mathrm{NaH}_{2} \mathrm{PO}_{4}$, and then the organic additive of ACN at $10 \%(\mathrm{v} / \mathrm{v})$ was mixed. The $\mathrm{pH}$ was adjusted to 7.1 with $1.0 \mathrm{M} \mathrm{NaOH}$. All solutions entering the capillary were filtered through a $0.22 \mu \mathrm{m}$ filter membrane to prevent clogging of capillaries. The electrophoretic separation was obtained using a voltage of $+15 \mathrm{kV}$. The capillary temperature was maintained at $25{ }^{\circ} \mathrm{C}$. SAs were monitored at $195 \mathrm{~nm}$ and an ordinary pressure injection was 0.5 psi for $5 \mathrm{~s}(1 \mathrm{psi}=6894.76 \mathrm{~Pa})$.

\subsection{PAEKI conditions}

The optimized BGE solution was prepared according to the above conditions. In the PAEKI, firstly, the BGE was filled into the whole capillaries, then the water plug was introduced for $9 \mathrm{~s}$ at a pressure of $0.5 \mathrm{psi}(3.45 \mathrm{kPa})$, and the sample was injected for $30 \mathrm{~s}$ at a voltage of $-10 \mathrm{kV}$ while the assisted pressure was $0.5 \mathrm{psi}$.

\section{Results and discussion}

\subsection{Optimization of CZE conditions}

To achieve satisfactory separations, the CZE parameters were optimized taking the resolution and migration time as the principle figures of merit with concurrent judicious consideration of efficiency. In this work, the effects of electrolyte solution (type, $\mathrm{pH}$, concentration), organic additive (type, contents), and separation voltage were investigated and optimized, respectively. During the optimization procedure, all the experimental conditions were identical except the variable parameters to optimize. For each parameter optimization, five parallel experiments were carried out.

The type of electrolyte solution has a great influence on the migration of substances. Herein, two types of commonly used separation buffer solutions including borate buffer and phosphate buffer were tested. The results showed that borate buffer could not effectively separate SAs along with peak broadening, while phosphate buffer could well separate the six SAs. So, phosphate buffer was used as the electrolyte solution.

The concentration of electrolyte solution directly affects Zeta potential of capillary inner wall. At the low electrolyte solution concentration, the Zeta potential and EOF are large, which will lead to short migration time and incomplete separation (Nowak et al., 2015). Increasing the concentration of electrolyte solution is beneficial to reduce Zeta potential and EOF and thereby improve separation. So, the effects of different concentrations $(10,20,30$ and $40 \mathrm{mM})$ of phosphate buffer were examined. In Fig. S1, when the buffer concentration was 10 $\mathrm{mM}$, the first peak of SMZ and the last peak of SFA presented a good base-line separation, while the second wide peak (SMR plus SMM) and the third one (SDZ plus SMX) weren't completely separated; at the other three concentrations, similar phenomena occurred but with a base-line separation between the second and third peaks. So, $10 \mathrm{mM}$ was not used. At 30 and $40 \mathrm{mM}$ phosphate buffer, the electrophoretic currents not only were quite high but also fluctuated drastically, which would affect the accuracy of the measurement results. In addition, high concentration buffer solution would increase Joule heating effect and thereby cause poor reproducibility (Wang et al., 2018). Therefore, 20 $\mathrm{mM}$ was used as the phosphate buffer concentration in the subsequent experiments.

The $\mathrm{pH}$ of the electrolyte solution affects the charge of analytes, and thus in turn affects the migration rate in the electrolyte solution. The $\mathrm{p} K_{\mathrm{a}}$ values of SMZ, SMR, SMM, SDZ, SMX and SFA are 7.4, 6.8, 6.5, 6.4, 5.6 and 5.3, respectively (Fig. 1), so in order to have these compounds in their ionic form for their proper separation, the $\mathrm{pH}$ of the electrolyte solution was tested in weak acid or weak alkaline conditions. Therefore, different $\mathrm{pH}$ values (5.5, 7.1, 8.5 and 9.1) of $20 \mathrm{mM} \mathrm{NaH}{ }_{2} \mathrm{PO}_{4}$ were investigated. SAs are amphoteric compounds, and thus, behave both as acids and as bases depending on the solution pH (Font et al., 2007). The lower the $\mathrm{p} K_{\mathrm{a}}$ is, the greater the net negative charge and mobility in the opposite direction to the EOF, and the longer the migration time is (Ricci and Cross, 1993). Therefore, the migration order of the six SAs is positively correlated with their respective $\mathrm{p} K_{\mathrm{a}}$ values, namely SMZ first, followed by SMR, SMM, SDZ, SMX and SFA, as shown in Fig. 2C and S2. Fig. S2 shows that the six SAs have desirable peak resolutions at $\mathrm{pH} 7.1$, and only a slight peak-overlap appeared between SMM and SDZ. Therefore, a pH of 7.1 for $20 \mathrm{mM} \mathrm{NaH}_{2} \mathrm{PO}_{4}$ was selected for subsequent experiments.

In electrophoretic analysis, organic additives can effectively improve the separation degree or selectivity. $\mathrm{ACN}$, acetone, $\mathrm{MeOH}$ and EtOH with the same volume fraction were respectively added into phosphate buffer. Fig. S3 shows that ACN can be used as organic modifier to get the best separation within the shortest time. After investigating the content of $\operatorname{ACN}(5,10,15$, and $20 \%(\mathrm{v} / \mathrm{v}))$, the results showed that $10 \%$ ACN had the best effect, because all the SAs attained higher resolution (except a slight peak-overlap between SMM and SDZ) in shorter migration time. Fig. S4 shows that the addition of $10 \%$ and $15 \%$ ACN can both separate the six SAs well, and the migration time and peak area were approximately similar under these two additions. For the sake of saving solvent and consuming least organic solvent, 10 $\%$ ACN was added to the phosphate buffer for further experiments. It should be pointed out that the volume of organic additives should not be too high, otherwise it decreases the conductivity of BGE and the stacking efficiency.

At the next stage, the impact of different separation voltages (10, 15,20 and $25 \mathrm{kV}$ ) was examined. As is well known, the analysis time was decreased by increasing the voltage. Compared with $20 \mathrm{kV}$, the migration time at $15 \mathrm{kV}$ was slightly prolonged, but the peak area and the resolution of each SA were higher. Considering that the wider peak may be attained in the subsequent PAEKI optimization, a superior resolution should be selected as far as possible. Therefore, a voltage of 15 $\mathrm{kV}$ was selected as the subsequent experimental condition.

Through the above experiments, the best conditions for CZE separation of the six SAs were confirmed as below: $20 \mathrm{mM}$ phosphate, $\mathrm{pH}$ 
7.1 as the electrolyte solution, $10 \%(\mathrm{v} / \mathrm{v}) \mathrm{ACN}$ as the organic additive and $15 \mathrm{kV}$ as the separation voltage.

\subsection{Optimization of PAEKI conditions}

Fig. 2 schematically illustrates the PAEKI procedure and its mechanism: firstly filling the capillary with BGE, then introducing a water plug under pressure, finally carrying out electric injection under the reverse voltage and applying assisted pressure at the same time. When the sample solution of the analytes enters the water plug, the accumulation is formed due to the change of conductivity and the decrease of velocity. Then, auxiliary pressure is used to balance the EOF and increase the injection amount, so as to attain the stacking enrichment of analytes. After the injection is completed, CZE separation is conducted for the analytes under an applied voltage. Herein, ultrapure water was used as the sample matrix to optimize the parameters affecting PAEKI, including injection voltage, injection time, assisted pressure and water plug length. When performing optimization, the identical conditions except for the being-optimized variable parameters were used. And all the optimization experiments were conducted five times.

When other conditions were fixed, different injection voltages $(4,6$, 8,10 , and $12 \mathrm{kV}$ ) in negative mode were optimized first. It was observed in Fig. 3A that with the increase of injection voltage, the peak area of the SAs gradually increased. When the injection voltage exceeded $10 \mathrm{kV}$, the peak area decreased significantly. Higher injection voltage would generate larger EOF (Gao et al., 2018) and the excessive EOF would push the analytes out of the capillary port, resulting in the accumulation decrease (Ma et al., 2019) and thereby peak area decrease, producing worse enrichment effect. In addition, if the voltage was too high, the current would easily cut off and the repeatability would become poor. Thus, $-10 \mathrm{kV}$ was selected as the injection voltage.

Using $-10 \mathrm{kV}$ electrokinetic injection, the effect of injection time in the range of $12,18,24,30$ and $36 \mathrm{~s}$ on the enrichment was tested. As shown in Fig. 3B, the peak areas were increased first and then decreased with the increase of injection time, while the highest peak areas of all SAs were achieved at $30 \mathrm{~s}$. This was probably owing to that the increase of injection time made more amounts of SAs accumulate at the sampleBGE interface. However, excessive accumulation would reduce the separation efficiency of CZE. Therefore, $30 \mathrm{~s}$ was selected as the injection time for the subsequent tests.

Under the condition of $-10 \mathrm{kV}$ and $30 \mathrm{~s}$ injection, the effect of assisted pressure $(0.2,0.3,0.4,0.5$ and $0.6 \mathrm{psi})$ on enrichment efficiency was examined. Applying assisted pressure can balance the reverse EOF and prevent the sample from being pushed out of the capillary. The trend of enrichment capacity was shown in Fig. 3C. Therefore, $0.5 \mathrm{psi}$ was the best assisted pressure for separation of six SAs.

In the case of injection voltage of $-10 \mathrm{kV}$, assisted pressure of 0.5 psi and injection time of $30 \mathrm{~s}$, the effect of water plug injection time (3, 6, 9, 12 and $15 \mathrm{~s}$ ) on the enrichment of six SAs was explored. According to the Bernoulli equation in the ESI, water plug length could be attained. Fig. 3D shows that when the length of water plug was $1.5 \mathrm{~cm}$ $(3.45 \mathrm{kPa} \times 9 \mathrm{~s})$, the maximum enrichment effect was attained. While the water plug was shorter than $1.5 \mathrm{~cm}$, ions in BGE easily diffused into the sample zone by the EOF, leading to the decrease of the enrichment effect. On the contrary, while the water plug was longer than $1.5 \mathrm{~cm}$, the total amount of analytes decreased and the enrichment capacity
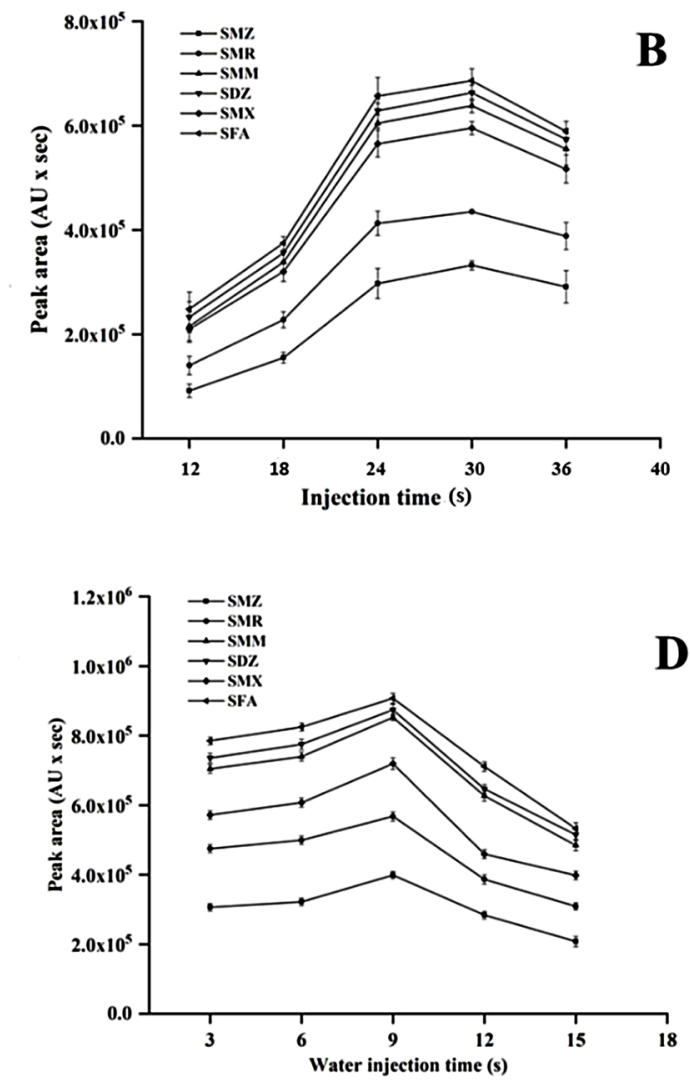

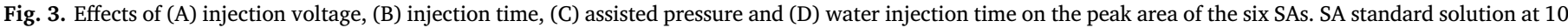

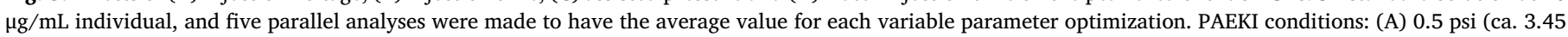

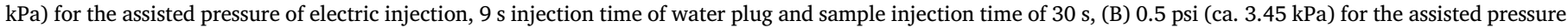

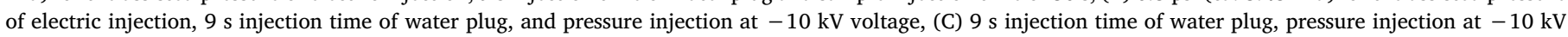

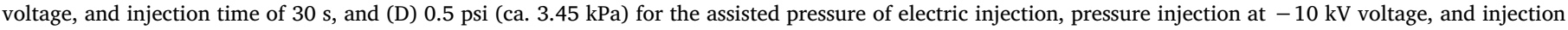
time of 30 s. CZE conditions: $20 \mathrm{mM} \mathrm{NaH}_{2} \mathrm{PO}_{4}, \mathrm{pH} 7.10$, and applied separation voltage of $15 \mathrm{kV}$. 


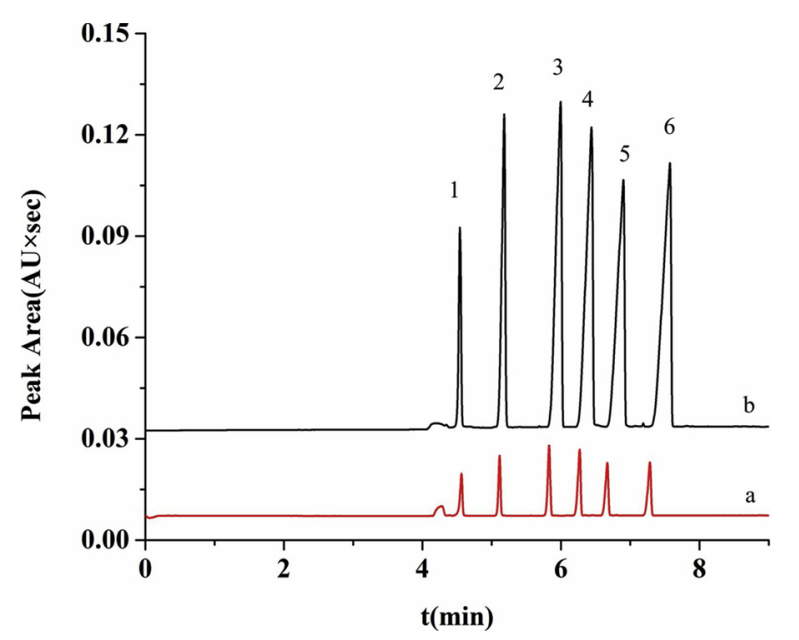

Fig. 4. Electropherograms of the six SAs from (a) CZE with normal pressure injection and (b) PAEKI-CZE. Injection conditions: (a) six SAs individual at 10 $\mu \mathrm{g} / \mathrm{mL}$ for $3.45 \mathrm{kPa} \times 5 \mathrm{~s}$ injection; (b) electrokinetic injection voltage $-10 \mathrm{kV}$ $\times 30 \mathrm{~s}$, $9 \mathrm{~s}$ injection water and assisted pressure of $3.45 \mathrm{kPa}$, and six SAs individual at $5 \mu \mathrm{g} / \mathrm{mL}$. CZE conditions: $20 \mathrm{mM} \mathrm{NaH}_{2} \mathrm{PO}_{4}$ at pH 7.10, and applied separation voltage of $15 \mathrm{kV}$. Peak identification: (1) SMZ, (2) SMR, (3) SMM, (4) SDZ, (5) SMX and (6) SFA.

also declined. Accordingly, a $1.5 \mathrm{~cm}$ water plug was employed.

To sum up, the optimum condition for PAEKI to enrich six SAS was: pre-pressure injection of $9 \mathrm{~s}$, water plug of $1.5 \mathrm{~cm}$, assisted pressure of $0.5 \mathrm{psi}$, and $-10 \mathrm{kV}$ electric injection for $30 \mathrm{~s}$.

\subsection{Method performance of the PAEKI-CZE}

Under the above-optimized conditions, the analytical characteristic of PAEKI-CZE method was assessed. In order to estimate the enrichment efficiency of PAEKI, the enrichment factor (EF) was calculated based on the peak area according to the following equation:

$E F=\frac{C_{P}}{C_{0}}$

where $C_{\mathrm{P}}$ and $C_{0}$ are the concentration of detected analytes after PAEKI and the initial concentration of analytes in the aqueous solution, respectively (Zhong et al., 2014).

As shown in Fig. 4a and b, all the six SAs were positively influenced by the PAEKI enrichment procedure, and the EFs for SMZ, SMR, SMM, SDZ, SMX, and SFA were $39,47,53,50,54$, and 62 , respectively.

Under the optimum PAEKI-CZE condition, none of SAs was detected in all the tested blank samples including three food samples and three water samples, as shown in Fig. 5a and Fig. S5a. It needs to be noted that PAEKI is susceptible to slight changes in sample composition, which may affect the efficiency and accuracy of the method (Aneta et al., 2015). In order to eliminate the matrix effect, the calibration curves were constructed by spiking blank milk, pork, egg, tap water, lake water and seawater samples with different concentrations. As shown in Table 1, the linear range of SMZ in the three food samples was $0.1-10 \mu \mathrm{g} / \mathrm{mL}$, and the linear ranges of other five SAs were $0.01-10 \mu \mathrm{g} /$ $\mathrm{mL}$ in milk, and $0.03-10 \mu \mathrm{g} / \mathrm{mL}$ in pork and egg samples. So, good linear relationships were attained for the six SAs while the correlation coefficients were within 0.9931-0.9994. In addition, Table S1 shows that the linear range of SMZ in tap water, lake water and seawater samples was $0.1-10 \mu \mathrm{g} / \mathrm{mL}$, the linear ranges of other five SAs were $0.01-10 \mu \mathrm{g} / \mathrm{mL}$ in tap water and seawater, and $0.02-10 \mu \mathrm{g} / \mathrm{mL}$ in lake water. The correlation coefficients within 0.9942-0.9989 suggested good linearity.

The limit of detection (LOD) was calculated based on the three times signal-to-noise ratio $(\mathrm{S} / \mathrm{N}=3)$ of the peak height of the target analytes. As listed in Table 1, the LODs of six SAs were in the range of

\section{Milk}

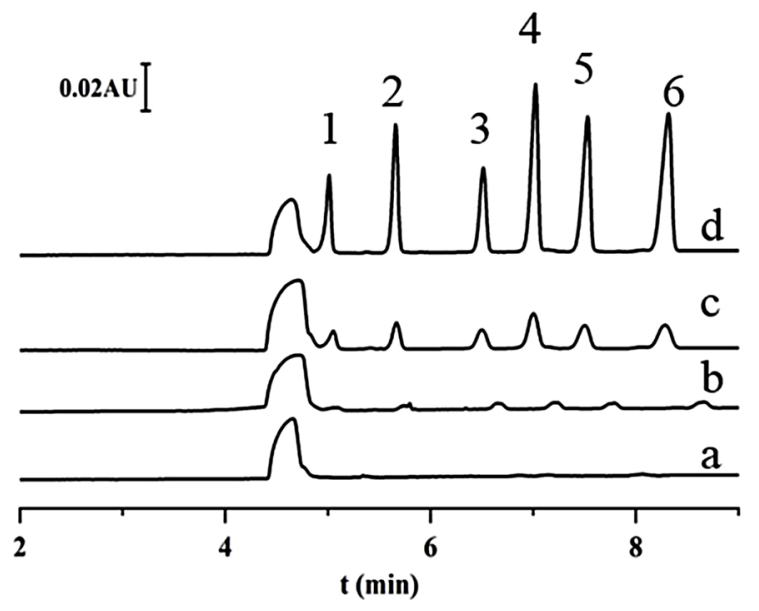

\section{Seawater}

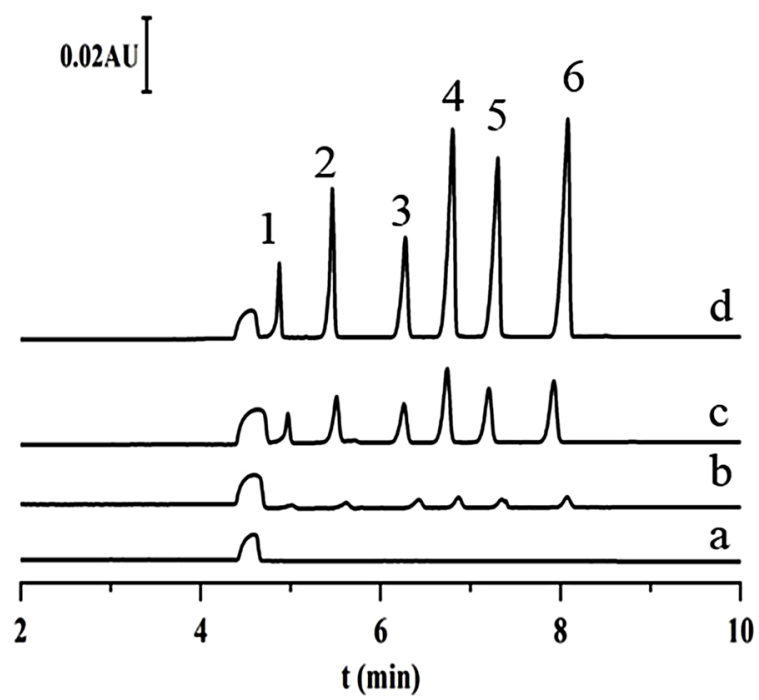

Fig. 5. Electropherograms of the six SAs after PAEKI-CZE in blank (a) and spiked samples of milk and seawater with six SAs individual at (b) $0.1 \mu \mathrm{g} / \mathrm{mL}$, (c) $2.0 \mu \mathrm{g} / \mathrm{mL}$ and (d) $10.0 \mu \mathrm{g} / \mathrm{mL}$. PAEKI-CZE conditions and peak identification were the same as described in Fig. $4 \mathrm{~b}$.

$0.0018-0.0163 \mu \mathrm{g} / \mathrm{mL}, 0.0083-0.0638 \mu \mathrm{g} / \mathrm{mL}$ and $0.0052-0.0478 \mu \mathrm{g} /$ $\mathrm{mL}$ for milk, pork and egg samples, respectively, which are far lower than the maximum allowable concentration of SAs $(0.1 \mu \mathrm{g} / \mathrm{mL})$ in animal-derived food prescribed by the European Union (Premarathne et al., 2017). Based on the 10 times signal-to-noise ratio $(\mathrm{S} / \mathrm{N}=10)$ of the peak height of SAs, the limit of quantitation (LOQ) of the method was calculated. The LOQs of six SAs in milk, pork and egg sample were $0.0061-0.0503 \mu \mathrm{g} / \mathrm{mL}, 0.0253-0.1826 \mu \mathrm{g} / \mathrm{mL}$, and 0.0164-0.1475 $\mu \mathrm{g} /$ $\mathrm{mL}$, respectively, and these are also lower than the required values by 
Table 1

Analytical performances of the PAEKI-CZE method for the determination of six SAs in food samples $(n=5)$.

\begin{tabular}{|c|c|c|c|c|c|c|}
\hline Food & SA & Regression equation $^{\mathrm{a}}$ & $r$ & Linear range $/(\mu \mathrm{g} / \mathrm{mL})^{\mathrm{b}}$ & $\mathrm{LOD} /(\mu \mathrm{g} / \mathrm{mL})^{\mathrm{c}}$ & $\mathrm{LOQ} /(\mu \mathrm{g} / \mathrm{mL})^{\mathrm{c}}$ \\
\hline \multirow[t]{6}{*}{ Milk } & SMZ & $y=41490 x-6105$ & 0.9945 & $0.1-10$ & 0.0163 & 0.0503 \\
\hline & SMR & $y=56188 x+512$ & 0.9951 & $0.01-10$ & 0.0046 & 0.0142 \\
\hline & SMM & $y=83608 x-495$ & 0.9983 & $0.01-10$ & 0.0148 & 0.0443 \\
\hline & SDZ & $y=85929 x+11328$ & 0.9968 & $0.01-10$ & 0.0018 & 0.0061 \\
\hline & SMX & $y=69939 x+12942$ & 0.9939 & $0.01-10$ & 0.0065 & 0.0198 \\
\hline & SFA & $y=88908 x+1150$ & 0.9987 & $0.01-10$ & 0.0026 & 0.0068 \\
\hline \multirow[t]{6}{*}{ Pork } & SMZ & $y=42931 x+1842$ & 0.9974 & $0.1-10$ & 0.0638 & 0.1826 \\
\hline & SMR & $y=58623 x+1048$ & 0.9962 & $0.03-10$ & 0.0212 & 0.0655 \\
\hline & SMM & $y=84962 x-689$ & 0.9994 & $0.03-10$ & 0.0641 & 0.2047 \\
\hline & SDZ & $y=86437 x+721$ & 0.9980 & $0.03-10$ & 0.0083 & 0.0253 \\
\hline & SMX & $y=63922 x+14058$ & 0.9968 & $0.03-10$ & 0.0295 & 0.0851 \\
\hline & SFA & $y=88472 x-1759$ & 0.9975 & $0.03-10$ & 0.0092 & 0.0261 \\
\hline \multirow[t]{6}{*}{ Egg } & SMZ & $y=41964 x-679$ & 0.9967 & $0.1-10$ & 0.0478 & 0.1495 \\
\hline & SMR & $y=56842 x-4183$ & 0.9958 & $0.03-10$ & 0.0150 & 0.0488 \\
\hline & SMM & $y=83981 x+632$ & 0.9964 & $0.03-10$ & 0.0429 & 0.1434 \\
\hline & SDZ & $y=84035 x-11249$ & 0.9942 & $0.03-10$ & 0.0052 & 0.0164 \\
\hline & SMX & $y=67029 x+1742$ & 0.9978 & $0.03-10$ & 0.0237 & 0.0697 \\
\hline & SFA & $y=88762 x+748$ & 0.9931 & $0.03-10$ & 0.0085 & 0.0319 \\
\hline
\end{tabular}

\footnotetext{
a $y$ means peak area and $x$ means concentration $(\mu \mathrm{g} / \mathrm{mL})$

b Based on peak area.

c Based on peak height.
}

Table 2

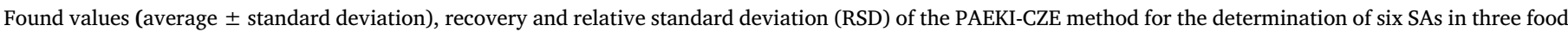
samples $(n=5)$.

\begin{tabular}{|c|c|c|c|c|c|c|c|c|c|c|}
\hline \multirow[t]{2}{*}{ SA } & \multirow{2}{*}{$\begin{array}{l}\text { Spiked } \\
(\mu \mathrm{g} / \mathrm{mL})\end{array}$} & \multicolumn{3}{|l|}{ Milk } & \multicolumn{3}{|l|}{ Pork } & \multicolumn{3}{|l|}{ Egg } \\
\hline & & Found $\pm \mathrm{SD}(\mu \mathrm{g} / \mathrm{mL})$ & $\begin{array}{l}\text { Recovery } \\
(\%)\end{array}$ & $\begin{array}{l}\text { RSD } \\
(\%)\end{array}$ & $\begin{array}{l}\text { Found } \pm \text { SD } \\
(\mu \mathrm{g} / \mathrm{mL})\end{array}$ & $\begin{array}{l}\text { Recovery } \\
(\%)\end{array}$ & $\begin{array}{l}\text { RSD } \\
(\%)\end{array}$ & $\begin{array}{l}\text { Found } \pm \text { SD } \\
(\mu \mathrm{g} / \mathrm{mL})\end{array}$ & $\begin{array}{l}\text { Recovery } \\
(\%)\end{array}$ & $\begin{array}{l}\text { RSD } \\
\text { (\%) }\end{array}$ \\
\hline \multirow[t]{3}{*}{ SMZ } & 0.1 & $0.102 \pm 0.006$ & 102 & 5.9 & $0.098 \pm 0.004$ & 98 & 4.1 & $0.096 \pm 0.003$ & 96 & 3.1 \\
\hline & 2 & $1.87 \pm 0.07$ & 94 & 3.7 & $1.97 \pm 0.11$ & 99 & 5.6 & $2.03 \pm 0.05$ & 101 & 2.5 \\
\hline & 10 & $10.23 \pm 0.36$ & 102 & 3.5 & $10.75 \pm 0.47$ & 108 & 4.4 & $9.40 \pm 0.17$ & 94 & 1.8 \\
\hline \multirow[t]{3}{*}{ SMR } & 0.1 & $0.095 \pm 0.003$ & 95 & 3.2 & $0.102 \pm 0.006$ & 102 & 5.9 & $0.097 \pm 0.006$ & 97 & 6.2 \\
\hline & 2 & $1.78 \pm 0.12$ & 89 & 6.7 & $2.06 \pm 0.15$ & 103 & 7.3 & $1.97 \pm 0.04$ & 98 & 2.0 \\
\hline & 10 & $9.33 \pm 0.45$ & 93 & 4.8 & $9.58 \pm 0.44$ & 96 & 4.6 & $10.13 \pm 0.40$ & 101 & 3.9 \\
\hline \multirow[t]{3}{*}{ SMM } & 0.1 & $0.091 \pm 0.003$ & 91 & 3.3 & $0.104 \pm 0.003$ & 104 & 2.9 & $0.095 \pm 0.003$ & 95 & 3.2 \\
\hline & 2 & $2.07 \pm 0.09$ & 104 & 4.4 & $2.26 \pm 0.05$ & 113 & 2.2 & $2.00 \pm 0.11$ & 100 & 5.5 \\
\hline & 10 & $10.01 \pm 0.28$ & 101 & 2.8 & $10.32 \pm 0.37$ & 103 & 3.6 & $9.63 \pm 0.54$ & 96 & 5.6 \\
\hline \multirow[t]{3}{*}{ SDZ } & 0.1 & $0.098 \pm 0.005$ & 98 & 5.1 & $0.097 \pm 0.003$ & 97 & 3.1 & $0.102 \pm 0.005$ & 102 & 4.9 \\
\hline & 2 & $1.95 \pm 0.13$ & 97 & 6.7 & $1.93 \pm 0.10$ & 97 & 5.2 & $2.00 \pm 0.04$ & 100 & 2.0 \\
\hline & 10 & $9.60 \pm 0.38$ & 96 & 4.0 & $10.47 \pm 0.61$ & 105 & 5.8 & $10.43 \pm 0.46$ & 104 & 4.4 \\
\hline \multirow[t]{3}{*}{ SMX } & 0.1 & $0.107 \pm 0.006$ & 107 & 5.6 & $0.109 \pm 0.007$ & 109 & 6.4 & $0.104 \pm 0.006$ & 104 & 5.8 \\
\hline & 2 & $2.09 \pm 0.09$ & 105 & 4.3 & $1.95 \pm 0.13$ & 98 & 6.7 & $2.02 \pm 0.17$ & 101 & 8.4 \\
\hline & 10 & $10.42 \pm 0.58$ & 104 & 5.6 & $10.97 \pm 0.48$ & 110 & 4.4 & $10.28 \pm 0.26$ & 103 & 2.5 \\
\hline \multirow[t]{3}{*}{ SCM } & 0.1 & $0.096 \pm 0.003$ & 96 & 3.1 & $0.106 \pm 0.004$ & 106 & 3.8 & $0.103 \pm 0.007$ & 103 & 6.8 \\
\hline & 2 & $1.81 \pm 0.03$ & 91 & 1.7 & $2.06 \pm 0.08$ & 103 & 3.9 & $1.91 \pm 0.03$ & 96 & 1.6 \\
\hline & 10 & $9.80 \pm 0.35$ & 98 & 3.6 & $10.28 \pm 0.62$ & 103 & 6.0 & $10.92 \pm 0.45$ & 109 & 4.1 \\
\hline
\end{tabular}

the Ministry of Agriculture of China (Announcement, 2002) that SAs should not exceed $100 \mu \mathrm{g} / \mathrm{kg}$ (SMZ should not exceed $25 \mu \mathrm{g} / \mathrm{kg}$ ) in food of animal origin. Meanwhile, the LODs for the tap, lake and sea water samples were $0.0021-0.0152 \mu \mathrm{g} / \mathrm{mL}, 0.0104-0.0675 \mu \mathrm{g} / \mathrm{mL}$ and $0.0097-0.0595 \mu \mathrm{g} / \mathrm{mL}$, respectively, as well as the LOQs were $0.0072-0.0413 \mu \mathrm{g} / \mathrm{mL}, 0.0314-0.1752 \mu \mathrm{g} / \mathrm{mL}$ and $0.0337-0.1981 \mu \mathrm{g} /$ $\mathrm{mL}$, respectively (Table S1). The more complicated samples have the LODs with higher values because the LOD extremely depends on the matrix components, the method and nature of the analyte. Therefore, the LODs in food samples were larger than that in water samples, which is very likely owing to the higher complexity of food samples than water samples.

The intra-day and inter-day precisions of the developed method were studied by using six SAs mixed standard solution with a concentration of $1 \mathrm{mg} / \mathrm{L}$, with 5 consecutive injections in one day and consecutive injections in 5 days, respectively, both using 5 parallel samples. As shown in Table S2, the intra-day precisions (relative standard deviation (RSD), $n=5$ ) of migration time and peak area were from 0.13 to $0.52 \%$ and from 1.17 to $3.54 \%$, respectively. And the inter-day precisions of migration time and peak area were $1.28-2.19 \%$ and $2.28-4.56 \%$, respectively. These results demonstrated that PAEKI enrichment combined with CZE detection is qualified for trace analysis of the six SAs in the tested food and water samples.

\subsection{Analysis of food and water samples}

In order to further evaluate the applicability of the developed method for different types of actual samples, the PAEKI-CZE was applied to analyze six SAs in milk, pork, eggs, tap water, lake water and seawater samples. In this regards, different concentrations of SAs were spiked in the food and water samples (Fig. 5 and Fig. S5). The average recoveries were calculated based on the average of the concentrations of five parallel samples and evaluate the feasibility of the method for actual samples analysis. As listed in Table 2, the recoveries of six SAs for milk, pork and egg samples were 89-107 \%, 96-113\% and 95-109\%, with RSDs of $1.7-6.7 \%, 2.2-7.3 \%$ and 1.6-6.8 \%, respectively. The 
water samples also attained satisfactory results as listed in Table S3. High recoveries (above $89 \%$ ) along with satisfactory precisions (less than $7.3 \%$ ) proved the developed PAEKI-CZE method was feasible for the determination of trace SAs in such real samples of animal husbandry products and environmental waters.

\section{Conclusions}

In conclusion, a new PAEKI-CZE-UV method was established for simultaneous enrichment/determination of six SAs in several food and water samples. The PAEKI enrichment strategy not only effectively improved the detection sensitivity in CZE-UV but also greatly simplified sample treatment. The established PAEKI-CZE-UV demonstrated good EFs, satisfactory linearity, high recovery and precisions as well as low cost for rapid concurrent determination. On the whole, the PAEKI was simple, fast and highly automated, and should be utilized in combination with various possible offline and/or online enrichment techniques to further elevate the detectability of CE-UV towards trace analytes in complicated matrices.

\section{Declaration of Competing Interest}

The authors have declared no conflict of interest.

\section{Acknowledgments}

This work was financially supported by the National Natural Science Foundation of China (21876199), the 13th Five-Year Plan for National Key Research and Development Projects (2017YFF0211304), the Chinese Academy of Sciences President's International Fellowship Initiative (2019PC0050), and the Taishan Scholar Project Special Funding (ts20190962).

\section{Appendix A. Supplementary data}

Supplementary material related to this article can be found, in the online version, at doi:https://doi.org/10.1016/j.jfca.2020.103462.

\section{References}

Announcement No. 235 of the Ministry of Agriculture of the People's Republic of China, 2002.

Aneta, J.B., Anna, M.P., Edward, S., 2015. Optimization of cheese sample preparation methodology for free amino acid analysis by capillary isotachophoresis. J. Food. Compos. Anal. 40, 136-142.

Brugnerotto, P., Betta, F.D., Gonzaga, L.V., Fett, R., Costa, A.C.O., 2019. A capillary electrophoresis method to determine aliphatic organic acids in bracatinga honeydew honey and floral honey. J. Food Compos. Anal. 82, 103243.

Chen, C., Meng, L.C., Li, M.X., Zhu, Z.W., 2015a. Simultaneous separation and sensitive detection of four b2-agonists in biological specimens by CE-UV using a field-enhanced sample injection method. Anal. Methods 7 (1), 175-180.

Chen, Y.L., Huang, Y.C., Wang, C.C., 2015b. Direct assay of uroporphyrin and coproporphyrin in human urine by reverse-mode field amplified sample injection-sweeping and micellar electrokinetic chromatography. Talanta 143, 27-34.

Chen, Z.P., Yu, C., Xi, J.B., Tang, S., Bao, T., Zhang, J., 2019. A hybrid material prepared by controlled growth of a covalent organic framework on amino-modified MIL-68 for pipette tip solid-phase extraction of sulfonamides prior to their determination by HPLC. Microchim. Acta 186 (5), 393-404.

Chui, M.Q., Thang, L.Y., See, H.H., 2017. Integration of the free liquid membrane into electrokinetic. J. Chromatogr. A 1481, 145-151.

Cysewski, P., Jeliński, T., 2019. Optimization, thermodynamic characteristics and solubility predictions of natural deep eutectic solvents used for sulfonamide dissolution. Int. J. Pharm. 570, 118682.

D’Ulivo, L., Feng, Y.L., 2015. Expanding the scope of pressure-assisted electrokinetic injection for online concentration of positively charged analytes in capillary electrophoresis-mass spectrometry. Electrophoresis 36 (7-8), 1024-1027.

Dasenaki, M.E., Thomaidis, N.S., 2010. Multi-residue determination of seventeen sulfonamides and five tetracyclines in fish tissue using a multi-stage LC-ESI-MS/MS ap proach based on advanced mass spectrometric techniques. Anal. Chim. Acta 672 (1-2), 93-102.

Font, G., Garcia, A.J., Pico, Y., 2007. Pressurized liquid extraction combined with capillary electrophoresis-mass spectrometry as an improved methodology for the determination of sulfonamide residues in meat. J. Chromatogr. A 1159 (1), 233-241.
Fuh, M.R.S., Chu, S.Y., 2003. Quantitative determination of sulfonamide in meat by solidphase extraction and capillary electrophoresis. Anal. Chim. Acta 499 (1), 215-221.

Gao, F.F., Liu, J.Y., Lu, W.H., Li, J.H., Liu, H.T., 2018. Determination of four phenolic estrogens in water samples by pressure-assisted electrokinetic injection coupled with capillary electrophoresis. Chin. J. Chromatogr. 36 (6), 573-577.

Gao, F.F., Chen, X.X., Li, X.B., Li, J.H., Liu, H.T., Chen, L.X., 2019. Field-amplified sample injection combined with capillary electrophoresis for the simultaneous determination of five chlorophenols in water samples. Electrophoresis 40 (14), 1771-1778.

He, T., Xu, Z.Q., Ren, J., 2019. Pressure-assisted electrokinetic injection stacking for seven typical antibiotics in waters to achieve $\mu \mathrm{g} / \mathrm{L}$ level analysis by capillary electrophoresis with UV detection. Microchem. J. 146, 1295-1300.

Hoff, R., Kist, T.B.L., 2009. Analysis of sulfonamides by capillary electrophoresis. J. Sep. Sci. 32 (5), 854-866.

Jastrzebska, A., Piasta, A.M., Szłyk, E., 2015. Optimization of cheese sample preparation methodology for free amino acid analysis by capillary isotachophoresis. J. Food Anal 40, 136-142.

Lahcen, A.A., Guzmán, J.J.G., Santander, J.M.P., Aguilera, L.C., Amine, A., 2019. Fast route for the synthesis of decorated nanostructured magnetic molecularly imprinted polymers using an ultrasound probe. Ultrason. Sonochem. 53, 226-236.

Lara, F.J., Campana, A.M.G., Neusüss, C., Barrero, F.A., 2009. Determination of sulfonamide residues in water samples by in-line solid-phase extraction-capillary electrophoresis. J. Chromatogr. A 1216 (15), 3372-3379.

Lechtenberg, M., Hensel, A., 2019. Determination of glucosinolates in broccoli-based dietary supplements by cyclodextrin-mediated capillary zone electrophoresis. J. Food Anal. 78, 138-149.

Li, S.Y., Zhang, C.L., Wang, Y., 2009. Determination and correlation of aqueous solubilities for sulfonamides. Chin. Comput. Appl. Chem. 26 (10), 1349-1352.

Li, J.H., Lu, W.H., Ma, J.P., Chen, L.X., 2011. Determination of mercury(II) in water samples using dispersive liquid-liquid microextraction and back extraction along with capillary zone electrophoresis. Microchim. Acta 175, 301-308.

Li, M.S., Chen, X.Y., Guo, Y., Zhang, B.Y., Tang, F.X., Wu, X.P., 2016. Enhanced sensitivity and resolution for the analysis of paralytic shellfish poisoning toxins in water using capillary electrophoresis with amperometric detection and field-amplified sample injection. Electrophoresis 37 (23-24), 3109-3117.

Lu, W.H., Wang, X.Y., Wu, X.Q., Liu, D.Y., Chen, L.X., Zhang, X.S., 2017. Multi-template imprinted polymers for simultaneous selective solid-phase extraction of six phenolic compounds in water samples followed by determination using capillary electrophoresis. J. Chromatogr. A 1483, 30-39.

Ma, Y.L., Wen, Y.Y., Li, J.H., Wang, H., Ding, Y.J., Chen, L.X., 2013. Determination of three phenoxyacid herbicides in environmental water samples by the application of dispersive liquid-liquid microextraction coupled with micellar electrokinetic chromatography. Cent. Eur. J. Chem. 11 (3), 394-403.

Ma, S.Y., Gao, F.F., Lu, W.H., Zhou, N., You, H.Y., Li, J.H., Chen, L.X., 2019. Dispersive liquid-liquid microextraction coupled with pressure-assisted electrokinetic injection for simultaneous enrichment of seven phenolic compounds in water samples followed by determination using capillary electrophoresis. J. Sep. Sci. 42 (13), 2263-2271.

Martins, M.T., Barreto, F., Hoff, R.B., Jank, L., Arsand, J.B., Motta, T.M.C., Schapoval, E.E.S., 2016. Multiclass and multi-residue determination of antibiotics in bovine milk by liquid chromatography-tandem mass spectrometry: combining efficiency of milk control and simplicity of routine analysis. Int. Dairy J. 59, 44-51.

Memon, A.F., Palabiyik, I.M., Solangi, A.R., Memon, S.Q., Mallah, A.B., 2019. Large volume sample stacking (LVSS) in capillary electrophoresis (CE) with response surface methodology (RSM) for the determination of phenolics in food samples. Anal. Lett. 52 (18), 2853-2867.

Mohammad-Razdari, R., Ghasemi-Varnamkhasti, M., Izadi, Z., Rostami, S., Ensafi, A.A. Siadat, M., Losson, E., 2019. Detection of sulfadimethoxine in meat samples using a novel electrochemical biosensor as a rapid analysis method. J. Food. Compos. Anal. $82,103252$.

Nowak, P., Wozniakiewicz, M., Koscielniak, P., 2015. Application of capillary electrophoresis in determination of acid dissociation constant values. J. Chromatogr. A 1377, 1-12.

Pan, M.F., Wang, X.J., Wang, J.P., Lu, Y., Qian, K., Wang, S., 2016. Stable and sensitive detection of sulfonamide residues in animal-derived foods using a reproducible surface plasmon resonance immunosensor. Food Anal. Methods 10 (6), 2027-2035.

Parab, S.R., Amritkar, P.N., 2012. Development and validation of a procedure for determination of sulfonamide residues in pasteurized milk using modified QuEChERS method and liquid chromatography/tandem mass spectrometry. J. AOAC Int. 95 (5), 1528-1533.

Pérez, J.F.H., Manzanares, N.A., Havlíková, L., Gracia, L.G., Solich, P., Campana, A.M.G. 2016. Method optimization and validation for the determination of eight sulfonamides in chicken muscle and eggs by modified QuEChERS and liquid chromatography with fluorescence detection. J. Pharm. Biomed. Anal. 124, 261-266.

Premarathne, J.M.K.G.K., Satharasinghe, D.A., Gunasena, A.R.C., Munasinghe, D.M.C., Abeynayake, P., 2017. Establishment of a method to detect sulfonamide residues in chicken meat and eggs by high-performance liquid chromatography. Food Control $72,276-282$.

Qi, M.Y., Tu, C.Y., Li, Z.Q., Wang, W.P., Chen, J.R., Wang, A.J., 2018. Determination of sulfonamide residues in honey and milk by HPLC coupled with novel graphene oxide/polypyrrole foam material-pipette tip solid phase extraction. Food Anal. Methods 11 (10), 2885-2896.

Ricci, M.C., Cross, R., 1993. Capillary electrophoresis separation of sulphonamides and dihydrofolate reductase inhibitors. J. Miro Sep. 5 (3), 207-215.

Sacher, F., Lang, F.T., Brauch, H.J., Blankenhorn, I., 2001. Pharmaceuticals in groundwaters analytical methods and results of a monitoring program in BadenWurttemberg, Germany. J. Chromatogr. A 938 (1-2), 199-210.

Santos, B., Lista, A., Simonet, B.M., Rios, A., Valcárcel, M., 2004. Screening and analytical 
confirmation of sulfonamide residues in milk by capillary electrophoresis-mass spectrometry. Electrophoresis 26, 1567-1575.

Shelver, W.L., Shappell, N.W., Franek, M., Rubio, F.R., 2008. ELISA for sulfonamides and its application for screening in water contamination. J. Agric. Food Chem. 56 (15), 6609-6615.

Sun, H.W., Qi, H.J., Li, H., 2013. Development of capillary electrophoretic method combined with accelerated solvent extraction for simultaneous determination of residual sulfonamides and their acetylated metabolites in aquatic products. Food Anal. Methods 6 (4), 1049-1055.

Wang, P., Luo, J.H., 2018. Simultaneous determination of 9 sulfonamides in pork by UPLC-MS-MS. Chin. Appl. Chem. Ind. 47 (10), 2292-2295.

Wang, W.F., Yang, J.L., Shi, Y.P., 2018. Quality evaluation of six bioactive constituents in goji berry based on capillary electrophoresis field amplified sample stacking. Electrophoresis 12 (16), 2117-2124.

Wang, Z.Y., Guo, H.T., Chen, M., Zhang, G.B., Chang, R.M., Chen, A.J., 2019. Separation and determination of corynoxine and corynoxine B using chiral ionic liquid and hydroxypropyl- $\beta$-cyclodextrin as additives by field-amplified sample stacking in capillary electrophoresis. Electrophoresis 39 (17), 2195-2201.

Wang, M.T., Peng, B., Zhao, N., Xiong, Z.L., Wang, Y., Zhao, L.S., 2020. Multiresidue analysis of tetracycline and $\beta$-receptor agonists in chicken by pressurized liquid extraction and liquid chromatography-tandem mass spectrometry: comparison with QuEChERS extraction method and ultrasound assisted extraction. J. Food. Compos. Anal. 85, 103339.

Xia, L., Liu, L.J., Lv, X.X., Qu, F., Li, G.L., You, J.M., 2017. Towards the determination of sulfonamides in meat samples: a magnetic and mesoporous metal-organic framework as an efficient sorbent for magnetic solid phase extraction combined with high-performance liquid chromatography. J. Chromatogr. A 1500, 24-31.

Xu, Z.Q., Li, A.M., Wang, Y.L., Chen, Z.L., Hirokawa, T., 2014. Pressure-assisted electrokinetic injection stacking for verteporfin drug to achieve highly sensitive enantioseparation and detection in artificial urine by capillary electrophoresis. J. Chromatogr. A 1355, 284-290.

Yi, J., Zeng, L.W., Wu, Q.Y., Yang, L.R., Xie, T.Y., 2018. Sensitive simultaneous determination of synthetic food colorants in preserved fruit samples by capillary electrophoresis with contactless conductivity detection. Food Anal. Methods 11 (6), 1608-1618.

Zhang, H.J., Gavina, J., Feng, Y.L., 2011a. Understanding mechanisms of pressure-assisted electrokinetic injection: application to analysis of bromate, arsenic and selenium species in drinking water by capillary electrophoresis-mass spectrometry. J. Chromatogr. A 1218 (20), 3095-3104.

Zhang, H.J., Zhu, J.P., Feng, Y.L., 2011b. On-line enrichment and measurement of four halogenated phenols in water samples using pressure-assisted electrokinetic Injection-tandem mass spectrometry. Anal. Sci. 26 (11), 1157-1162.

Zhong, X., Ai, L., Yong, W., Zhi, C., Takeshi, H., 2014. Pressure-assisted electrokinetic injection stacking for verteporfin drug to achieve highly sensitive enantioseparation and detection in artificial urine by capillary electrophoresis. J. Chromatogr. A. 1355, 284-290.

Zhang, Z.X., Liu, Y.J., Wang, Q., Wang, J.J., 2019. Capillary electrophoresis and quantum dot electrochemiluminescence by micellar reversed sweeping. Acta Chim. Sin. 77 (2), 179-183. 